\title{
Increase in exhaled nitric oxide levels in patients with difficult asthma and correlation with symptoms and disease severity despite treatment with oral and inhaled corticosteroids
}

\author{
R G Stirling, S A Kharitonov, D Campbell, D S Robinson, S R Durham, K F Chung, \\ P J Barnes for the Asthma and Allergy Group
}

\begin{abstract}
Background-Patients with difficult asthma suffer chronic moderate to severe persistent asthma symptoms despite high doses of inhaled and oral corticosteroid therapy. These patients suffer a high level of treatment and disease related morbidity but little is known about the degree of airway inflammation in these patients.

Methods-Fifty two patients were examined to assess levels of exhaled nitric oxide (NO) as a surrogate marker of inflammatory activity in this condition. From this group, 26 patients were defined with severe symptoms and current physiological evidence of reversible airway obstruction requiring high dose inhaled ( $\geqslant 2000 \mu \mathrm{g}$ beclomethasone dipropionate (BDP) equivalent) or oral steroid therapy to maintain disease control.

Results-Exhaled NO levels were higher in subjects with difficult asthma (mean $13.9 \mathrm{ppb}, 95 \%$ CI 9.3 to 18.5 ) than in normal controls $(7.4 \mathrm{ppb}, 95 \%$ CI 6.9 to $7.8 ; \mathbf{p}<0.002$ ), but lower than levels in steroid naive mild asthmatics (36.9 ppb, 95\% CI 34.6 to $39.3 ; p<0.001)$. Prednisolone treated patients had higher exhaled NO levels than patients only requiring inhaled corticosteroids (17.5 ppb, 95\% CI 11.1 to 24.0 versus $7.2 \mathrm{ppb}, 95 \%$ CI 4.6 to 9.8 ; p = 0.016 ), suggesting greater disease severity in this group. Non-compliance with prednisolone treatment was observed in $20 \%$ of patients but this did not explain the difference between the treatment groups. Exhaled NO levels were closely correlated with symptom frequency $(p=0.03)$ and with rescue $\beta$ agonist use $(p<0.002)$, but they did not correlate with lung function. Conclusions-Exhaled NO may serve as a useful complement to lung function and symptomatology in the assessment of patients with chronic severe asthma, and in the control and rationalisation of steroid therapy in these patients.

(Thorax 1998;53:1030-1034)
\end{abstract}

Keywords: exhaled nitric oxide; inflammatory markers; difficult asthma

Difficult asthma is characterised by uncontrolled symptoms and a failure to respond to usual "adequate treatment". ${ }^{1}$ Patients fre- quently require maintenance oral corticosteroids and have inhaled corticosteroid requirements of more than $2 \mathrm{mg}$ per day. Disease impact in these patients is increased by uncontrolled symptoms, a higher exacerbation rate, high dose therapy, and the adverse effects of this therapy. Although patient numbers are relatively small, the significance of this group results from their disproportionate morbidity and consumption of resources.

Monitoring asthma activity has the potential to reduce morbidity and, indeed, forms the basis for current management guidelines. ${ }^{23}$ Peak expiratory flow (PEF) is currently used to monitor disease control but may not reflect the degree of inflammation in the airways. Since bronchial biopsy (the gold standard for assessment of airway inflammation) is not generally feasible in severe disease, much effort is focused on less invasive measures of airway inflammation as these may provide guidance relating to both treatment and prognosis.

Biopsy specimens of the bronchial wall show increased numbers of eosinophils in patients with asthma $\mathrm{a}^{4}$ and this is reflected in the airway lumen where eosinophils and eosinophil cationic protein (ECP) in induced sputum are increased during asthma exacerbations. ${ }^{67}$ Other indices of inflammation include hydrogen peroxide $\left(\mathrm{H}_{2} \mathrm{O}_{2}\right)$ in exhaled breath condensate, ${ }^{89}$ serum levels of ECP, ${ }^{10}{ }^{11}$ and urinary leukotriene E4 levels. ${ }^{12}{ }^{13}$ Each of these techniques is beset by technical and handling difficulties which make them relatively impractical as routine tests for serial disease monitoring.

Measurement of exhaled nitric oxide (NO) levels provides a rapid, reproducible, and reliable test which may reflect airway inflammation in asthma. ${ }^{14} 15$ The increase in exhaled NO levels in asthma exacerbations is thought to be due chiefly to activation of airway iNOS induced by inflammatory cytokines. ${ }^{16}$ In support of this notion, $\mathrm{NO}$ is increased in acute exacerbations of asthma ${ }^{17}$ and is suppressed by corticosteroids. ${ }^{18}$ Persistent elevation of NO in treated patients may then suggest either more severe inflammation or inadequately treated inflammation.

The correlation between symptomatology, lung function, and exhaled NO levels was therefore assessed in 26 patients with difficult asthma to determine its role in this condition. 
Table 1 Characteristics of patients with difficult asthma

\begin{tabular}{ll}
\hline No. & 26 \\
Sex (F/M) & $19 / 7$ \\
Mean (SD) age (range) & $38.8(15.0)$ years $(15-71)$ \\
$\quad$ Women & $37.9(15.6)$ \\
$\quad$ Men & $41.0(12.4)$ \\
Years symptomatic & $19.2(15.1)$ \\
Atopic status & Atopic/non-atopic 20/6 \\
No. of smokers & 5 \\
Treatment: & $\mathrm{n}=17(12 \mathrm{~F} / 5 \mathrm{M})$ \\
$\quad$ Prednisolone & $2025(1197) \mu \mathrm{d} /$ day \\
ICS Fluticasone $(\mathrm{n}=20)$ & $3967(2271) \mu \mathrm{g} /$ day \\
ICS Budesonide $(\mathrm{n}=6)$ & $8.1(9.9) \mathrm{puffs} /$ day \\
Rescue $\beta$ agonist MDI & \\
Lung function: & $64.2(20.5)$ \\
$\quad$ PEF (\% predicted) & $66.2(21.6)$ \\
FEV $(\%$ predicted) & $63.0(16.4)$ \\
FEV $1 /$ FVC & $67.1(29.5)$ \\
PEFV (\% mean) & 19.7 (median), $0-36$ (range) \\
$\beta$ agonist response &
\end{tabular}

ICS = inhaled corticosteroid MDI = multidose inhaler; $\mathrm{PEF}=$ peak expiratory flow; $\mathrm{FEV}_{1}=$ forced expiratory volume in one second; FVC = forced vital capacity; PEFV = diary card peak expiratory flow variability values are mean (SD) or median (range) where indicated.

\section{Methods}

PATIENTS

We reviewed 52 consecutive patients from a tertiary asthma referral centre with the clinical problem of "difficult asthma" of which 26 met the following inclusion criteria: (1) current physiological evidence of reversible airways obstruction; (2) maintenance oral prednisolone requirement, or (3) inhaled corticosteroid ( $\geqslant 2 \mathrm{mg} /$ day BDP or equivalent); (4) moderate to severe persistent asthma symptoms ${ }^{3}$; and (5) stable disease with no evidence of exacerbation or infection within the preceding two weeks.

Physiological criteria for reversible airways obstruction included a bronchodilator response to inhaled salbutamol $200 \mu \mathrm{g}$ in baseline forced expiratory volume in one second $\left(\mathrm{FEV}_{1}\right)$ of $\geqslant 15 \%$ predicted $(\mathrm{n}=17)$, diurnal variation in peak expiratory flow (PEF) of $\geqslant 20 \%$ ( $\mathrm{n}=9$ ), and concentration of methacholine required to provoke a fall in $\mathrm{FEV}_{1}$ of more than $20 \%\left(\mathrm{PC}_{20}\right)$ of $\leqslant 8 \mathrm{mg} / \mathrm{ml}(\mathrm{n}=1)$. Seventeen patients were dependent on oral steroids although not all were challenged by dose reduction. The characteristics of the patients are shown in table 1 . A comparison was made with 46 normal subjects aged 32 (4) years (six atopic, $\mathrm{FEV}_{1} 95.5$ (5)\% predicted, $\mathrm{PC}_{20}$ methacholine $>16 \mathrm{mg} / \mathrm{ml}$ ) and 30 steroid naive mild asthmatic subjects aged 28 (5) years (30 atopic, $\mathrm{FEV}_{1} 91$ (4)\% predicted, $\mathrm{PC}_{20}$ $<3.3 \mathrm{mg} / \mathrm{ml}$ ) and these patients have been described elsewhere. ${ }^{19}$

Chronic bronchitis was detected in a single subject (airflow obstruction with normal gas transfer, chronic cough, and no evidence of bronchiectasis on computed tomographic (CT) scan), but no other pulmonary comorbidity was detected after clinical review, lung function testing, chest radiography, and CT scanning.

SYMPTOM SCORES AND DIARY CARDS

Subjects were provided with two week diary cards to record daily symptoms, morning (prebronchodilator) and afternoon (postbronchodilator) PEF, and rescue $\beta$ agonist use (puffs per day). Subjects were asked to score daily each symptom of cough, chest tightness, wheeze, sputum, breathlessness, and night time symptoms on a scale of $0-3(0=$ no symptoms, $1=$ mild, $2=$ moderate, and $3=$ severe $)$. Daily symptoms were averaged over a two week period. On enrolment subjects estimated symptom frequency on a scale of $0-5$ where 0 $=$ no symptoms for three months; $1=$ symptoms less than weekly or on exercise; $2=$ symptoms more than weekly but less than daily; $3=$ daily but not at night; $4=$ daily and night-time symptoms less than twice a week; and $5=$ daily with night-time symptoms more than twice a week.

\section{PULMONARY FUNCTION TESTS}

Home PEF measurements were made using the Wright peak flow meter. Spirometric lung function was measured by a standard technique (Jaeger, Market Harborough, Leics, UK).$^{20}$ Maximum bronchodilator reversibility (\% change from baseline \% predicted $\mathrm{FEV}_{1}$ ) was established by spirometric testing before and after staged inhalation of salbutamol $200 \mu \mathrm{g}$ from a metered dose inhaler without spacer followed by $2.5 \mathrm{mg}$ salbutamol delivered by nebuliser. Diary card PEF variability (PEFV) was calculated as maximum PEFminimum $\mathrm{PEF} /$ mean $\mathrm{PEF} \times 100 \%$.

\section{EXHALED NITRIC OXIDE MEASUREMENTS}

Exhaled NO was measured using a chemiluminescence analyser (Model LR 2000; Logan Research, Rochester, Kent, UK) sensitive to $1-5000 \mathrm{ppb} \mathrm{NO}$ with a resolution of $0.3 \mathrm{ppb}$ and response time of $<0.5$ seconds. Measurements were made following inhalation to total lung capacity with slow exhalation through a wide bore Teflon tube to residual volume. An expiratory pressure of $3(0.4) \mathrm{mm} \mathrm{Hg}$ was maintained by a visual display of expiratory flow, thus excluding nasal NO contamination. ${ }^{21}$ NO sampling by the analyser was via a side arm with a constant flow rate of $250 \mathrm{ml} / \mathrm{min}$. NO measurement was made at the end of exhalation when both $\mathrm{NO}$ and $\mathrm{CO}_{2}$ levels had achieved a stable plateau phase, representing alveolar sampling.

Measurements were made at least twice and the highest of two concordant readings $( \pm 5 \%)$ was recorded. Rescue $\beta$ agonist use prior to testing was unrestricted. Subjects who smoked refrained from doing so for 24 hours prior to testing. There were five smokers (2-10 cigarettes/day), of whom three took prednisolone and had NO values of 20.5, 30.0 and $9.3 \mathrm{ppb}$, respectively, while the two on inhaled corticosteroids alone had values of 57.6 and $3.2 \mathrm{ppb}$.

\section{PREDNISOLONE ASSAYS}

Serum prednisolone levels were measured using an HPLC technique.

STATISTICAL ANALYSIS

Comparison between groups was made using Spearman rank correlation and Mann-Whitney non-parametric analysis, a $\mathrm{p}$ value of less than 0.05 being considered significant. 


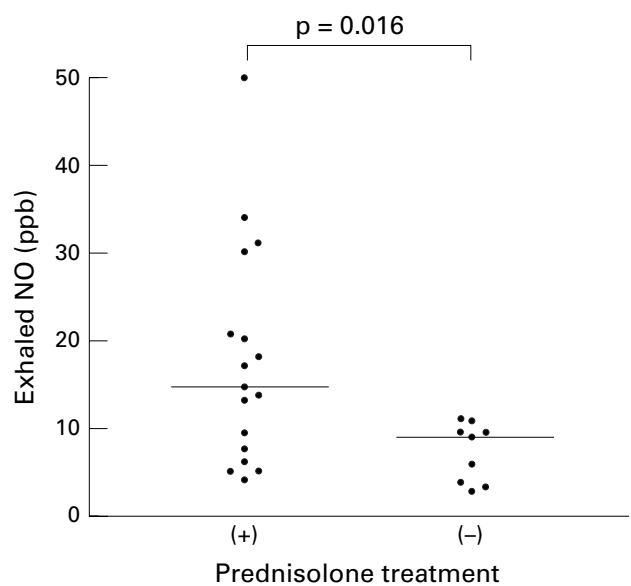

Figure 1 Exhaled NO levels in patients with difficult asthma treated and not treated with prednisolone.

\section{Results}

SYMPTOM FREQUENCY

Seventeen of 26 subjects experienced daily symptoms with night-time symptoms at least once a week and eight experienced symptoms more than twice a week. One patient had had no symptoms for three months.

LUNG FUNCTION

Lung function results varied with a mean $\mathrm{FEV}$, of 65.70 (21)\% predicted, closely matching the average $\mathrm{PEF} \%$ predicted and $\mathrm{FEV}_{1} / \mathrm{FVC}$ for the group (table 1 ). Diary peak flow variability (amplitude \% mean) was $69.8 \%$.

\section{EXHALED NITRIC OXIDE}

Exhaled NO levels were significantly higher in patients with difficult asthma (mean $13.9 \mathrm{ppb}$, $95 \%$ CI 9.3 to 18.5 ) than in normal subjects (7.4 ppb, 95\% CI 6.9 to $7.8 ; \mathrm{p}<0.002)$, and were significantly lower than levels in steroid naïve mild asthmatics (36.9 ppb, 95\% CI 34.6 to 39.3 ; $\mathrm{p}<0.001)$. NO levels were higher in subjects taking oral prednisolone $(17.5 \mathrm{ppb}$, $95 \%$ CI 11.1 to 24.0 ) than in those not taking prednisolone $(7.2 \mathrm{ppb}, 95 \% \mathrm{CI} 4.6$ to $9.8 ; \mathrm{p}=$ 0.016 ; fig 1).

Exhaled NO levels did not correlate with inhaled corticosteroid dose $(p=0.43)$. There was also no difference in NO levels between those on very high dose inhaled corticosteroids ( $\mathrm{n}=7,>2 \mathrm{mg} /$ day) and those on lower dose inhaled corticosteroids ( $\mathrm{n}=19, \leqslant 2 \mathrm{mg} /$ day), although two patients on very high dose inhaled corticosteroids were also taking oral prednisolone.

CORRELATION OF EXHALED NO WITH SYMPTOMS AND TREATMENT

Exhaled NO levels correlated with symptom frequency $(r=0.46, \mathrm{p}=0.03)$ and with rescue $\beta$ agonist use $(r=0.58, \mathrm{p}<0.002)$ (fig $2 \mathrm{~B}$ ). Furthermore, NO levels were significantly higher in those with the highest symptom frequency (symptom frequency $0-4$ versus $5, \mathrm{p}$ $=0.03)$. The average symptom score closely correlated with rescue $\beta$ agonist use $(p<0.002$; fig 2A) and NO levels were significantly higher in those requiring $\geqslant 10$ puffs per day than in those using $<10$ puffs of rescue $\beta$ agonist per
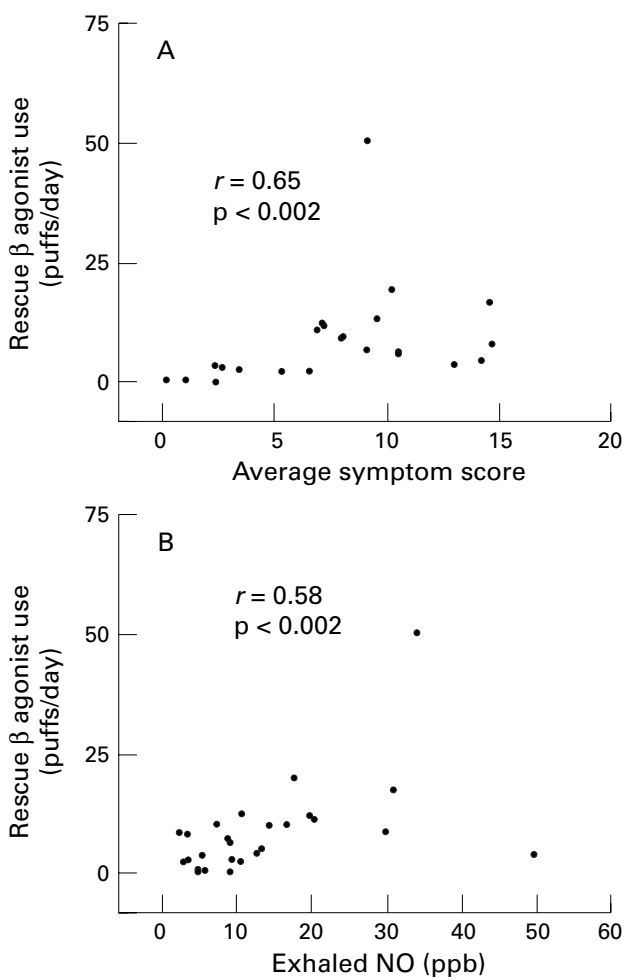

Figure 2 Correlation of daily rescue $\beta$ agonist use with (A) average daily symptom score $(r=0.65, p=0.002)$ and (B) exhaled NO levels $(r=0.58, p<0.002)$.

day $(p=0.008)$. Neither symptom frequency nor average symptom score correlated with inhaled corticosteroid dose.

Subjects treated with prednisolone had higher symptom frequency $(p<0.04)$ and rescue $\beta$ agonist use approached a significant difference $(p<0.07)$, but average symptom scores were not significantly different $(\mathrm{p}=$ $0.17)$.

\section{CORRELATION OF EXHALED NO WITH LUNG} FUNCTION

Exhaled NO levels for the group did not correlate with degree of airway obstruction $\left(\mathrm{FEV}_{1} \%\right.$ predicted, $\left.\mathrm{p}=0.73 ; \mathrm{FEV}_{1} / \mathrm{FVC}, \mathrm{p}=0.94\right)$, peak flow variability $(p=0.85)$, nor with $\beta$ agonist reversibility (bronchodilator response in $\left.\mathrm{FEV}_{1}, \mathrm{p}=0.95\right)$. Airway obstruction $\left(\mathrm{FEV}_{1} /\right.$ FVC) was significantly greater in those on high dose inhaled corticosteroids than in those on low dose inhaled corticosteroids $(p=0.004)$. Lung function was not significantly different between those treated with oral steroids and those not on oral treatment.

COMPLIANCE AND PREDNISOLONE ASSAYS

Prednisolone assays were obtained two hours after scheduled dose administration in 15 patients on oral prednisolone. In three assays $(20 \%)$ prednisolone levels were below detectable limits. Mean (SD) serum prednisolone levels were 344 (285) nmol/1. Prednisolone levels did not correlate with prednisolone dose $(\mathrm{p}=0.6)$ nor with exhaled NO levels ( $\mathrm{p}=$ 0.37). Patients with undetectable prednisolone levels were considered non-compliant but, when these three patients were excluded, NO 
levels were still significantly higher in prednisolone treated patients than in nonprednisolone treated patients $(\mathrm{p}=0.03)$.

\section{Discussion}

Patients with difficult asthma have moderate to severe persistent symptoms despite high dose anti-inflammatory treatment. This group had increased NO levels as a whole in spite of treatment. Furthermore, prednisolone treated patients had significantly higher NO levels than those not requiring oral corticosteroid treatment. A likely explanation for this finding is that this group has more severe disease and consequently attracts higher intensity treatment. A further explanation, however, is that these patients have NO levels that are unaffected or only minimally influenced by steroid therapy, thus possibly identifying subjects with relative steroid insensitivity. We believe that compliance as a confounding factor is effectively excluded by the high level of compliance as detected by serum prednisolone assays.

Symptom scores and symptom frequency in this group did not correlate with PEF variability or airway obstruction. Symptom scores were significantly increased in those with the highest symptom frequency. NO levels were closely correlated with rescue $\beta$ agonist use $(\mathrm{p}<0.002)$, but not significantly with average symptom score $(p=0.11)$. $\beta$ agonist use has not previously been associated with raised NO levels and, when taken in high doses, has no effect on exhaled $\mathrm{NO}^{22}$ and is thus unlikely to be causal in this relationship.

These findings suggest that, in patients with difficult asthma, there may be persistent airway inflammation despite treatment with oral corticosteroids. How these results relate to bronchial mucosal biopsy findings and other measures of airway inflammation, however, requires further study. Since NO concentrations correlated with symptom scores, symptoms in severe asthma may therefore be a marker of airway inflammation and this relationship also remains unclear.

A consideration of inflammatory markers in mild to moderate asthma is valuable. Laitinen et $a \bar{P}$ have shown an increase in airway mucosal eosinophil count associated with increased symptoms and bronchial hyperreactivity during exacerbations of asthma, all of which fall with inhaled corticosteroid treatment. Both oral and inhaled corticosteroids reduce asthma symptoms, rescue $\beta$ agonist use, and improve $\mathrm{FEV}_{1}$ while leading to significant reductions in epithelial and submucosal eosinophil counts. ${ }^{43}$ Similar correlations in changes are seen when serum ECP, ${ }^{24} \mathrm{~T}$ cell activation markers (CD4, CD25) in bronchoalveolar lavage fluid, ${ }^{25}$ and urinary leukotriene E4 levels ${ }^{12}$ are considered as surrogate markers of inflammation.

In mild to moderate disease there would thus appear to be a concordant change in symptoms, lung function, and inflammatory markers during exacerbations; however, in chronic severe disease a tendency to fixed airflow limitation due to changes in extracellular matrix and basement membrane thickening ${ }^{26-28}$ may cause symptoms, lung function, and inflammatory markers to vary discordantly. ${ }^{29}$ Small studies have shown that apparent control of airway inflammation does not necessarily control airway hyperresponsiveness or vice versa. ${ }^{30-32}$ We were unable to show a correlation between $\mathrm{FEV}_{1} / \mathrm{FVC}, \mathrm{PEF}$ variation, and symptom scores in this study and, indeed, a number of studies have reported a tendency to fixed airflow limitation in patients with chronic asthma. ${ }^{29} 3334$

The relationship of symptoms to inflammatory activity in severe and difficult asthma is unclear, ${ }^{35}$ but its importance lies in the choice of treatment response to symptoms. ${ }^{36}$ Exhaled NO combined with symptom score may be a useful tool for monitoring asthma control in patients with difficult/severe asthma where changes in lung function may have limited sensitivity. Furthermore, the identification of subjects in whom exhaled NO levels remain markedly increased in spite of high dose corticosteroid therapy may prompt consideration of relative steroid insensitivity or resistance, which may influence steroid therapy.

The identification of a surrogate marker of airway inflammation that may be conveniently used in the outpatient setting has the potential to serve as an indicator of the adequacy of antiinflammatory treatment. Such markers may help to rationalise steroid therapy in those already treated with high dose oral and inhaled corticosteroids, and complement symptomatology and lung function as measures of control in chronic severe or difficult asthma.

1 Chung KF. Management of difficult asthma. Br F Hosp Med 1994;51:80-1.

2 British Thoracic Society. The BTS guidelines on asthma management, 1995: review and position statement. Thorax 1997;52(Suppl 1):S1-21.

3 Lenfant C, Khaltaev N, eds. Global initiative for asthma. Global strategy for asthma management and prevention. NHLBI/ WHO Workshop Report No. 95-3659. Maryland: NIH, WHO 1996.

4 Djukanovic R, Wilson JW, Britten KM, et al. Effect of an inhaled corticosteroid on airway inflammation and symptoms in asthma. Am Rev Respir Dis 1992;145:669-74.

5 Laitinen LA, Laitinen A, Heino M, et al. Eosinophilic airway inflammation during exacerbation of asthma and its treatment with inhaled corticosteroid. Am Rev Respir Dis 1991;143:423-7.

6 Pizzichini MM, Pizzichini E, Clelland L, et al. Sputum in severe exacerbations of asthma: kinetics of inflammatory indices after prednisone treatment. Am f Respir Crit Care Med 1997;155:1501-8.

7 Ronchi MC, Piragino C, Rosi E, et al. Do sputum eosinophils and ECP relate to the severity of asthma? Eur Respir F 1997;10:1809-13.

8 Antczak A, Nowak D, Shariati B, et al. Increased hydrogen peroxide and thiobarbituric acid-reactive products in expired breath condensate of asthmatic patients. Eur Respir f 1997;10:1235-41.

9 Dohlman AW, Black HR, Royall JA. Expired breath hydrogen peroxide is a marker of acute airway inflammation in pediatric patients with asthma. Am Rev Respir Dis 1993;148:955-60.

10 Ahlstedt S. Clinical application of eosinophilic cationic protein in asthma. Allergy Proc 1995;16:59-62.

11 Roquet A, Hallden G, Ihre E, et al. Eosinophil activity markers in peripheral blood have high predictive value for bronchial hyperreactivity in patients with suspected mild asthma. Allergy 1996;51:482-8.

12 Drazen JM. Pharmacology of leukotriene receptor antagonists and 5-lipoxygenase inhibitors in the management of asthma. Pharmacotherapy 1997;17:22-30s.

13 Drazen JM, O'Brien J, Sparrow D, et al. Recovery of leukotrienes from the urine of patients with airway obstruction. Am Rev Respir Dis 1992;146:104-8.

14 Kharitonov SA, Yates DH, Robbins RA, et al. Increased nitric oxide in exhaled air of asthmatic patients. Lancet nitric oxide in exha

15 Barnes PJ. Exhaled nitric oxide: a new lung function test. Thorax 1996;51:233-7. 
16 Hamid Q, Springall JB, Riveros-Moreno P, et al. Induction of nitric oxide synthase in asthma. Lancet 1993;342:1510of $n$.

17 Massaro AF, Gaston B, Kita D, et al. Expired nitric oxide levels during treatment of acute asthma. Am $\mathcal{F}$ Respir Crit Care Med 1995;152:800-3.

18 Kharitonov SA, Yates DH, Barnes PJ. Inhaled glucocorticoids decrease nitric oxide in exhaled air of asthmatic patients. Am F Respir Crit Care Med 1996;153:454-7.

19 Kharitonov SA, Chung KF, Evans D, et al. Increased exhaled nitric oxide in asthma is mainly derived from the lower respiratory tract. Am $\mathcal{f}$ Respir Crit Care Med 1996;153:1773-80.

20 Recomendations of the British Thoracic Society and the Association of Respiratory Technicians and Physiologists. Guidelines for the measurement of respiratory function. Respir Med 1994;88:165-94.

21 Kharitonov SA, Alving K, Barnes PJ. ERS Task Force Report. Exhaled and nasal nitric oxide measurement: Report. Exhaled and nasal nitric oxide measurer

22 Yates DH, Kharitonov SA, Barnes PJ. Effect of short and long acting inhaled beta agonists on exhaled nitric oxide in long acting inhaled beta agonists on exhaled nitric
asthmatic patients. Eur Respir $\mathcal{F} 1997 ; 10: 1483-8$

23 Djukanovic R, Homeyard S, Gratziou C, et al. The effect of treatment with oral corticosteroids on asthma symptoms and airway inflammation. Am $\mathcal{F}$ Respir Crit Care Med 1997; 155:826-32.

24 Siergiejko Z, Zietkowski Z, Chyrek Borowska S. Effect of flunisolide on exacerbation of clinical symptoms, spirometric parameters, consumption of $\beta_{2}$-adrenergic drugs and levels of cortisol and ECP in serum of patients with bronchial asthma. Pneumonol Alergol Pol 1995;63(Suppl 2):7682

25 Robinson DS, Bentley AM, Hartnell A, et al. Activated memory T helper cells in bronchoalveolar lavage fluid from patients with atopic asthma: relation to asthma symptoms, ung function and bronchial responsiveness. Thorax 1993; 48:26-32.

26 Jeffery PK, Wardlaw AJ, Nelson FC, et al. Bronchial biopsies in asthma: an ultrastructural, quantitative study and correlation with hyperactivity. Am Rev Respir Dis 1989;140: $1745-53$

27 Roche WR, Beasley R, Williams JH, et al. Subepithelial fibrosis in the bronchi of asthmatics. Lancet 1989;ii:520-4.

28 Wilson JW, Li, X, Pain MCF. The lack of distensibility of asthmatic airways. Am Rev Respir Dis 1993;148:806-9.

29 Brown JP, Greville WH, Finucane KE. Asthma and irreversible airflow obstruction. Thorax 1984;39:131-6.

30 Sont JK, Han J, van Krieken JM, et al. Relationship between the inflammatory infiltrate in bronchial biopsy specimens and clinical severity of asthma in patients treated with inhaled steroids. Thorax 1996;51:496-502.

31 Chapman ID, Foster A, Morley J. The relationship between airway inflammation and hyperreactivity of the airways in airway inflammation and hyperreactivity

32 Lundgren R, Soderberg M, Horstedt P, et al. Morphological studies of bronchial biopsies from asthmatics before and after 10 years treatment with inhaled corticosteroids. Eur Resp f 1988;1:883-9.

33 Peat JK, Woolcock AJ, Cullen K. Rate of decline of lung function in subjects with asthma. Eur F Respir Dis 1987;70: 171-9.

4 Redington AE, Howarth PH. Airway wall remodelling in asthma. Thorax 1997;52:310-2.

35 Woolcock AJ. How does inflammation cause symptoms? Am F Respir Crit Care Med 1996;153:S21-2.

36 Dahl R, Martinatti LC, Boner AL. Monitoring of bronchial asthma. Respir Med 1997;91:581-6. 